\title{
Surface free energy and mechanical performance of LDPE/CBF composites containing toxic-metal free filler
}

\author{
Zhitong Yao ${ }^{\mathrm{a}, *}$, Jerry Y.Y. Heng ${ }^{\mathrm{b}}$, Senentxu Lanceros-Méndez ${ }^{\mathrm{c}}$, Alessandro Pegoretti ${ }^{\mathrm{d}}$, \\ Meisheng Xia ${ }^{\mathrm{e}}$, Junhong Tang ${ }^{\mathrm{a}}$, Weihong $\mathrm{Wu}^{\mathrm{a} \text {,* }}$ \\ ${ }^{a}$ College of Materials Science and Environmental Engineering, Hangzhou Dianzi University, Hangzhou 310018, China \\ b Department of Chemical Engineering, Imperial College London, South Kensington Campus, London SW7 2AZ, UK \\ c Centro/Departamento de Física, Universidade do Minho, 4710-057 Braga, Portugal \\ d Department of Industrial Engineering and INSTM Research Unit, University of Trento, Via Sommarive 9, 38123 Trento, Italy \\ e Ocean College, Zhejiang University, Zhoushan 316021, China
}

A R T I C L E I N F O

\section{Keywords:}

Heavy-metal contamination

Children's toys

Biofiller

Surface characterization

Mechanical performance

\begin{abstract}
A B S T R A C T
Heavy-metal contamination in children's toys is a widespread problem, and the international community has issued a series of safety standards to restrict and control the use of toxic metals in toys. In this work, a colored filler (CBF) was prepared using pearl oyster shell (POS) as the green raw material and azo dye as the colorant. Its surface properties were subsequently studied in comparison to those of POS powder using the inverse gas chromatography method. The dispersion surface free energy profiles for both CBF and POS showed that this component contributed the major part $(>70 \%)$ to the total surface free energy. The CBF possessed lower polar surface free energy and was relatively more hydrophobic. It also showed a lower thermodynamic work of cohesion, allowing its better dispersion in a low density polyethylene (LDPE) matrix. Mechanical performance studies showed that adding CBF could significantly increase the tensile strength, elastic modulus, flexural strength and flexural modulus of LDPE composites. The absence of toxic metals coupled with excellent mechanical performance makes the $\mathrm{CBF}$ an ideal candidate as a filler for children's toys fabrication.
\end{abstract}

\section{Introduction}

Coloring adds aesthetic appeal and enhances values to toys and other children's products. The most widely used colorants include dyes and pigments, which are distinguishable by their mode of application. Among them, inorganic pigments have been applied since ancient times [1], and are considered to have advantages over their organic counterparts in terms of heat and light stability. However, most inorganic pigments are derived from toxic or transition metals, such as $\mathrm{Cd}, \mathrm{Pb}, \mathrm{Cr}$, $\mathrm{Co}, \mathrm{Hg}$ and $\mathrm{Ce}$, which adversely affect the environment and represent a threat to human health [2]. These metals may be released and absorbed via saliva during mouthing, sweat during dermal contact or gastric fluids after ingestion $[3,4]$. Although direct release of these metals from plastics may be expected to be low due to the complex and strong polymer structure of toys, scenarios of repeated exposure pose significant concerns for children's health.

Mollusk shells (e.g. clam, oyster, mussel and pearl oyster shells), with their predominantly calcium carbonate $\left(\mathrm{CaCO}_{3}\right)$ content plus a small amount of biomacromolecules, can be used as a potential substitute for commercial $\mathrm{CaCO}_{3}$ filler [5]. Fombuena et al. [6] prepared epoxy resin composites incorporating seashells. Li et al. [7] reported excellent mechanical performance of polypropylene composites filled with Mytilus edulis shell. Mustata et al. [8] also investigated the thermal properties of composites based on epoxy resin and conch shells. Considering the increasing concern of toxic heavy metal contamination in plastics and the inherent mechanical properties of mollusk shell material, we attempted to prepare a colored filler (CBF) using pearl oyster shell (POS) as the green raw material and azo dye as the colorant. However, it has been well recognized that the nature of the filler e.g. its surface free energy, particle size, surface area, and structure-or degree of irregularity, influences its reinforcing ability. A better understanding of the filler's surface properties is critical to determining the most effective polymer reinforcement fillers. Therefore, in the present work, the surface properties of $\mathrm{CBF}$ were determined in comparison to those of POS powder using the inverse gas chromatography (IGC) method. In order to provide further evidence for its suitability in larger scale practical applications, Vicat softening temperature and the mechanical performance of LDPE/CBF composites

\footnotetext{
* Corresponding authors.

E-mail addresses: sxyzt@126.com (Z. Yao), jchwwh@163.com (W. Wu).
} 
were also investigated. Ultimately the work is aimed at probing the promising use of $\mathrm{CBF}$ in the masterbatch industry and, therefore, solving the significant problem of high levels of toxic metals in toys.

\section{Theoretical basis}

The basic theory of IGC is presented here and more details can be found elsewhere [9-16]. The surface free energy is defined as the average free energy per unit area surface of a material. The total free surface energy $\left(\gamma_{S}^{T}\right)$ is often the combination of dispersion $\left(\gamma_{S}^{D}\right)$ and polar $\left(\gamma_{S}^{P}\right)$ components. Dispersive (apolar) interactions, also known as Lifshitz-van der Waals interactions, consist of London, Keesom, and Debye interactions. Specific (polar) interactions explain other types of interactions, such as acid-base interactions, hydrogen bonding and $\pi$ bonding [17]. A standard method of surface characterization is that the $\gamma_{S}^{D}$ is first determined using a series of $n$-alkanes as probes (in this case, octane, nonane and decane); then the acid-base parameters can be calculated from polar probes (in this case, toluene, acetone, acetonitrile and dichloromethane[DCM]). For the calculation of $\gamma_{S}^{D}$, the Dorris-Gray method [18] is commonly used and thus was applied in this work. The contribution of acid-base properties of a solid is often obtained by first measuring the free energies of adsorption $\left(\Delta \mathrm{G}^{\mathrm{p}}\right)$ for different polar probes. From the $\Delta \mathrm{G}^{\mathrm{P}}$, we can calculate the acid-base numbers related to the polar surface free energy.

Knowledge of surface free energy differences between filler particles would allow an objective decision about the extent of the interaction between filler and polymer matrix and provide a hint on the dispersion ability of the filler within the polymer matrix or about the likely extent of filler agglomeration. The extent of filler-filler interaction can be quantified by the thermodynamic work of cohesion $\left(\mathrm{W}_{\mathrm{C}}\right)$, which in turn can be determined by IGC [19] according to the geometric mean equation [20-22]:

$W_{C}=2 \sqrt{\gamma_{S}^{D} \cdot \gamma_{S}^{D}}+2 \sqrt{\gamma_{S}^{P} \cdot \gamma_{S}^{P}}=2 \gamma_{S}^{T}$

Knowledge of the surface free energy and its components for CBF and POS, can be used to calculate the $\mathrm{W}_{\mathrm{C}}$ between filler particles.

\section{Experimental materials and methods}

\subsection{Materials}

Commercial LDPE $(2426 \mathrm{H})$ with a melt flow rate of $1.9 \mathrm{~g} / 10 \mathrm{~min}$ at $190{ }^{\circ} \mathrm{C}$ was supplied by Sinopec Maoming Company, China. Direct Red 28 dye (DR 28) was provided by Yiwu Yu Fang Pigment Co., Ltd., China. The polar and nonpolar probes (HPLC purity, 99.0\%) were purchased from Sigma-Aldrich (St-Louis, MO, USA). The raw pearl oyster shell was collected from a pearl-processing factory in Zhuji city, China. It was first washed to remove attached impurities, and then calcined at $350{ }^{\circ} \mathrm{C}$ to remove the stratum corneum. The dried powder was subjected to fine grinding to obtain the pearl oyster shell (POS) powder. XRD analysis indicated that the major crystalline phase of POS was calcite $\left(\mathrm{CaCO}_{3}\right.$, JCPDS card no. 86-2334). The chemical compositions were determined by X-ray fluorescence (XRF, Shimadzu XRF1800 ) and the results were as follows (wt\%): C $14.2 \%$, O $52.6 \%$, Ca $33.2 \%$.

\section{2. $C B F$ preparation}

POS powder was mixed with DR 28 and water at a weight ratio of 200:1:300. After vigorous stirring for $0.5 \mathrm{~h}$, the mixture was left standing for $24 \mathrm{~h}$, then filtered, and the filter cake dried. The dried cake was ground to obtain the CBF. Photographs of the POS and CBF powders are shown in Fig. 1. The volume-weighted distribution analysis showed that the mean and median particle sizes of the POS were 8.5 and $7.6 \mu \mathrm{m}$, respectively; of the $\mathrm{CBF}, 9.1$ and $7.6 \mu \mathrm{m}$, respectively. The
BET specific surface areas of POS and CBF were determined as 0.9 and $1.5 \mathrm{~m}^{2} / \mathrm{g}$, respectively, using the iGC Surface Energy Analyzer (iGCSEA, Surface Measurement Systems, Alperton, UK) [23].

\subsection{LDPE composites preparation}

Before mixing, the LDPE matrix and CBF powder were oven-dried at $80{ }^{\circ} \mathrm{C}$ overnight. A series of LDPE and CBF powders with different weight ratios $(100 / 0,98 / 2,95 / 5,90 / 10,85 / 15,80 / 20,70 / 30$ and $60 /$ 40) were mixed with $5 \mathrm{wt} \%$ compatilizer PE-g-MAH, $0.1 \mathrm{wt} \%$ antioxidant 168, $1.5 \mathrm{wt} \%$ lubricant TAF and $0.1 \mathrm{wt} \%$ mineral oil, using a SHJ35 parallel co-rotating twin screw extruder (Nanjing, China). The extruder has eleven independent temperature zones and temperatures were set at $200{ }^{\circ} \mathrm{C}$ (zones $1-3$ ), $205^{\circ} \mathrm{C}$ (zone 4-7) and $215^{\circ} \mathrm{C}$ (zone $8-11)$. The extrudates were pelletized, and a plastic injection-molding machine (MA900/260, Ningbo, China) was then used to prepare test specimens. The injection molding machine has five temperature zones and temperatures were set at $180{ }^{\circ} \mathrm{C}$ (zone 1-2), $200{ }^{\circ} \mathrm{C}$ (zone 3-4) and $185^{\circ} \mathrm{C}$ (zone 5). Photographs of the test specimens are displayed in Fig. 2.

\subsection{Characterization and tests}

Surface free energy characterization and specific surface area determination were both carried out using the iGC-SEA. The data were analyzed using the advanced Cirrus Plus Analysis Software of iGC-SEA. For all the experiments, approximately $300 \mathrm{mg}$ of powder were packed into individual dimethyldichlorosilane-treated glass columns. The samples were run at a series of surface coverages (2-16\%) with polar and nonpolar molecular probes to determine $\gamma_{S}^{D}$ and $\gamma_{S}^{P}$ as well as $\Delta \mathrm{G}^{\mathrm{p}}$. The sample column was preconditioned for $1 \mathrm{~h}$ at $343.15 \mathrm{~K}$ and $0 \% \mathrm{RH}$ with $10 \mathrm{ml} / \mathrm{min}$ helium carrier gas, under the same conditions as in the experiment. The retention times were determined with a flame ionization detector (FID) and methane gas was used as a noninteracting molecule to determine the dead volume.

Prior to any surface-energy-related experiments, the BET specific surface areas of the two samples were first determined via physical adsorption of ethanol molecules by Elution Method using the retention time at the maximum FID signal. The particle-size distributions of POS and CBF were determined using a Beckman LS13320 laser particle-size analyzer. Vicat softening temperature tests were conducted with a ZWK1302-B Thermal Deformation/VICAT Temperature tester (MTS Systems (China) Co., Ltd.), $10 \mathrm{~N}$ loaded at a heating rate of $50{ }^{\circ} \mathrm{C} / \mathrm{h}$. Uniaxial tensile tests on LDPE/CBF composites were conducted according to the ASTM D638 standard. Izod impact tests were carried out on unnotched specimens according to the ASTM D256 standard. Particle size distribution was determined using a Beckman LS13320 laser particle size analyzer.

\section{Results and discussion}

\subsection{Surface free energies}

The $\gamma_{S}^{T}, \gamma_{S}^{D}$ and $\gamma_{S}^{P}$ profiles of CBF and POS obtained from iGC-SEA are illustrated in Fig. 3. It can be observed that the $\gamma_{S}^{D}$ component of the samples contributed the major part ( $>70 \%)$ to the $\gamma_{S}^{T}$. In addition, it displayed a decreasing trend with increasing surface coverage and the highest-energetic sites occupying approximately $2 \%$ of the fillers. However, this decreasing trend became insignificant when the surface coverage was larger than $4 \%$. The difference in the measured absolute $\gamma_{S}^{D}$ values at low and high coverage indicated significant heterogeneity among the surface free energy sites-those at highest-energetic sites had approximately $20 \%$ higher absolute values of the surface free energy compared to those of the lowest-energetic sites. For POS, the calculated $\gamma_{S}^{D}$ fell into the range of $48.0-59.3 \mathrm{~mJ} / \mathrm{m}^{2}$ across the surface coverages measured; however, the $\mathrm{CBF}$ showed a lower range of 

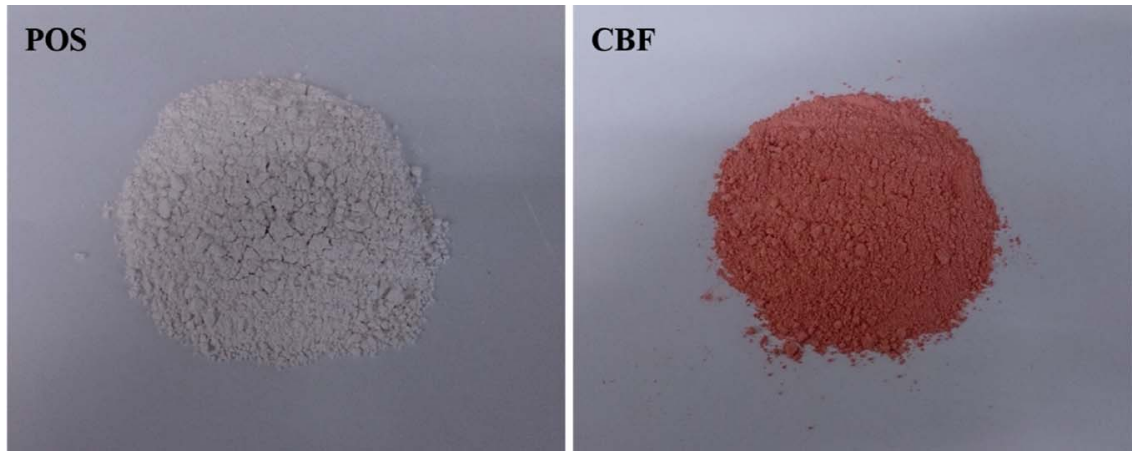

Fig. 1. Photographs of the POS and CBF powders.

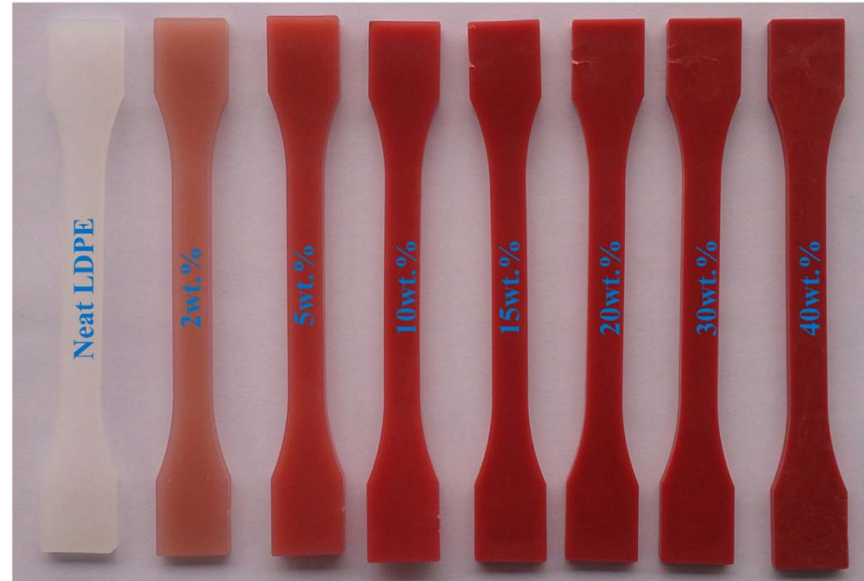

Fig. 2. Specimens for the mechanical performance studies of LDPE with increasing amounts of CBF.

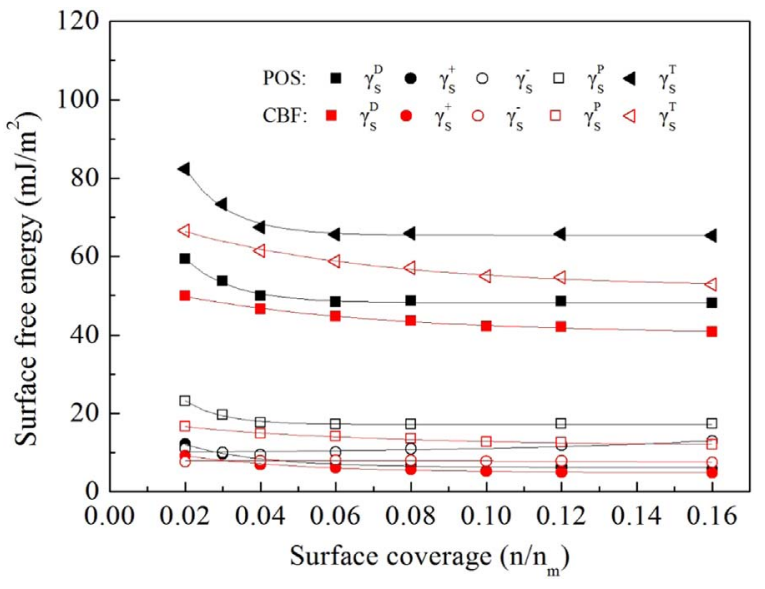

Fig. 3. Surface energy profiles for POS and CBF.

$40.8-49.9 \mathrm{~mJ} / \mathrm{m}^{2}$. It is worth noting that the $\gamma_{S}^{D}$ depends on the surface composition of the solid and the test temperature [24-26]. Schmitt et al. [27] reported that the modification of precipitated $\mathrm{CaCO}_{3}$ with chemicals such as hydroxy acids or silanes could decrease the $\gamma_{S}^{D}$. The work of Papirer et al. [28] revealed a drastic decrease in surface free energy for $\mathrm{CaCO}_{3}$ coated with stearic acid $\left(44.4 \mathrm{~mJ} / \mathrm{m}^{2}\right.$ for untreated and $29 \mathrm{~mJ} / \mathrm{m}^{2}$ for stearic acid-treated $\mathrm{CaCO}_{3}$ at $70{ }^{\circ} \mathrm{C}$ ). Jeong et al. [29] also reported a lower $\gamma_{S}^{D}$ value for stearic acid-treated ground $\mathrm{CaCO}_{3}$ $\left(93.3 \mathrm{~mJ} / \mathrm{m}^{2}\right.$ for untreatred and $34.8 \mathrm{~mJ} / \mathrm{m}^{2}$ for $1.5 \mathrm{wt} \%$ stearic acidtreated $\mathrm{CaCO}_{3}$ ). In this work, a decrement of $\gamma_{S}^{D}$ for CBF was also observed, which might be ascribed to its more uniform surface after loading with DR 28.

Compared to $\gamma_{S}^{D}$, the $\gamma_{S}^{P}$ component evidently contributed less to $\gamma_{S}^{T}$ : approximately $26.6 \%$ and $23.7 \%$ for POS and CBF, respectively, implying a lower polarity and more hydrophobicity for both samples.

$\gamma_{S}^{T}$ can be determined by summing $\gamma_{S}^{D}$ and $\gamma_{S}^{P}$ according to the Fowkes theory [30], so that the higher $\gamma_{S}^{D}$ and $\gamma_{S}^{P}$ components for POS add up to a higher $\gamma_{S}^{T}$ value. $\gamma_{S}^{T}$ was also found to be significantly decreased at lower surface coverages for both samples. According to Eq. (1), $\mathrm{W}_{\mathrm{C}}$ is equivalent to $2 \gamma_{S}^{T}$. Thus, the $\mathrm{W}_{\mathrm{C}}$ between filler particles was calculated as $130.60-164.82 \mathrm{~mJ} / \mathrm{m}^{2}$ for POS and $105.57-133.11 \mathrm{~mJ} /$ $\mathrm{m}^{2}$ for $\mathrm{CBF}$ at various surface coverages. POS showed higher $\mathrm{W}_{\mathrm{C}}$ values than $\mathrm{CBF}$, by $12.8-19.2 \%$ across all coverages, indicating a higher tendency to aggregate. $\mathrm{CBF}$ showed comparatively lower $\mathrm{W}_{\mathrm{C}}$ values, which could reduce the filler particle-particle interactions, allowing its better dispersion in a polymer matrix.

\subsection{Specific Gibbs free energy profiles}

The surface properties of fillers also depend on the ability to participate in specific interactions resulting from the presence of polar functional groups on the surface of the material. The $\Delta G^{p}$ profiles as a result of the interactions with four polar probes (toluene, acetone, acetonitrile and DCM) for CBF and POS are displayed in Fig. 4. $\Delta G^{p}$ changed as a function of surface coverage, further confirming the heterogeneous nature of the two samples. In Fig. 4, similar curves were generated for CBF and POS, although POS showed higher polar surface energies. The decreasing rank order for $\Delta G^{p}$ interactions was: acetonitrile $>$ acetone $>$ DCM $>$ toluene, which was consistent with the order of solvent polarity [31,32]. Both samples showed a strong degree of interaction with all the polar probes, but predominantly with acetonitrile, and to a lesser extent with toluene. It is worth noting that CBF possessed a relatively lower polar surface free energy, indicating a more hydrophobic nature.

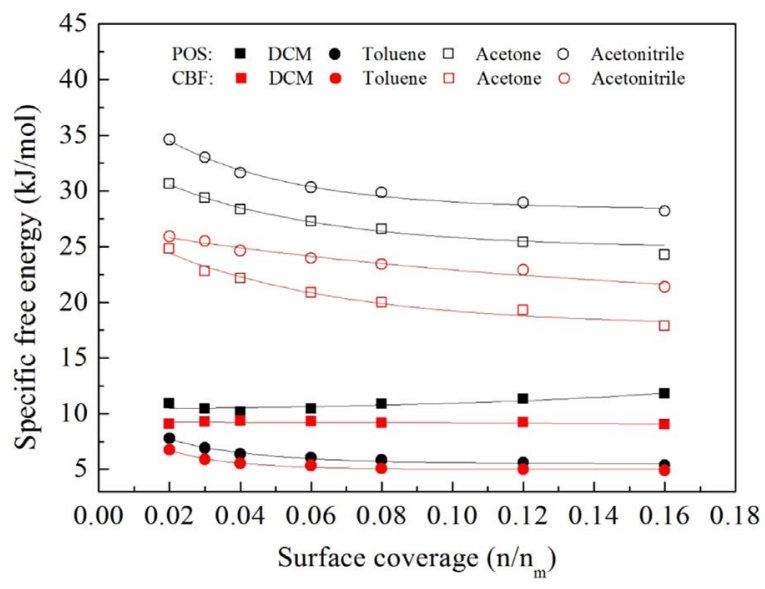

Fig. 4. Specific Gibbs free energy profiles of polar probes for POS and CBF. 


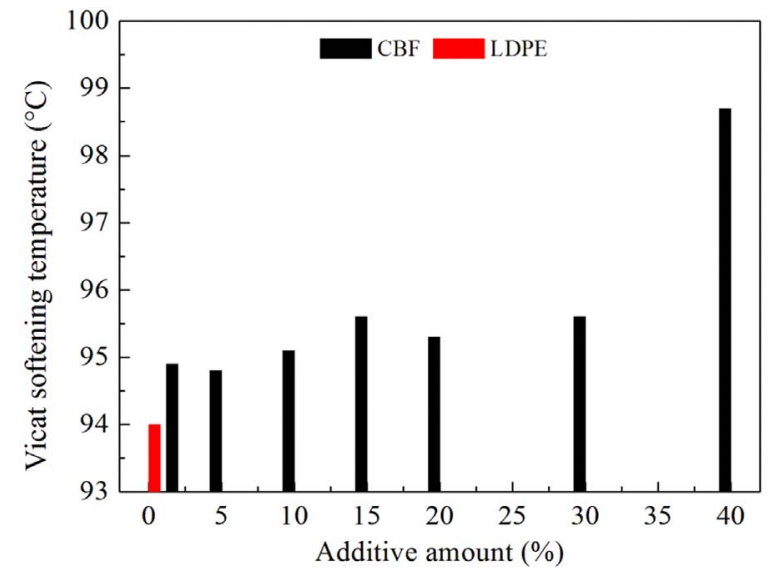

Fig. 5. Vicat softening temperature of neat LDPE and LDPE filled with CBF.

\subsection{Vicat softening temperature of $L D P E / C B F$ composites}

Vicat softening temperature (VST), an important indicator for heat resistance, is the determination of the softening point for materials, such as plastics. As can be seen in Fig. 5, the VST exhibited an overall increasing trend with increasing CBF content. As compared with that of neat LDPE $\left(94.0^{\circ} \mathrm{C}\right)$, the VST of the composite materials increased by $0.9-4.7^{\circ} \mathrm{C}$, indicating an improvement in heat resistance. This may be attributed to that the fact that the combination of LDPE and CBF restricted the movement of LDPE molecular chains.

\subsection{Mechanical properties of LDPE/CBF composites}

The mechanical properties of LDPE/CBF composites are displayed in Fig. 6. For comparison, the neat LDPE is also included. It can be seen that the tensile strength of the specimens increased significantly as CBF increased. It increased from 12.65 to $14.13 \mathrm{MPa}$, with a filler loading increase of $5-40 \mathrm{wt} \%$. The tensile strength is more dependent on the strength of filler-matrix adhesion [33]. Its increase might result from a good adhesion between the CBF and the LDPE matrix, which created strong interface regions and benefited load transfer from the ductile matrix to the strong filler, and thus reinforced the composite [33].

The elongation at break of the LDPE composites decreased almost linearly, with a CBF loading greater than $5 \mathrm{wt} \%$, because the composites became stiffer with increasing $\mathrm{CBF}$ content. As compared with the neat LDPE (171.6\%), this value decreased from 166.4 to $75.2 \%$ as the CBF incorporation increased from 2 to $40 \mathrm{wt} \%$. This substantial reduction was ascribed to the low elongation of the filler and the strong interaction with the polymer, restricting thus flow of polymer molecules [34].

In Fig. 6, a continuous increase in tensile elastic modulus is demonstrated with the incorporation of CBF. As compared with that for the neat LDPE (110.1 MPa), it increased from 137.2 to $313.3 \mathrm{MPa}$ with filler loading increasing from 2 to $40 \mathrm{wt} \%$. This apparent increase in Young's modulus can be attributed to increased filler-matrix interfacial interaction and enhanced load transmission from the polymer matrix to the reinforcement.

There was an overall increase in flexural strength and flexural modulus for LDPE composites filled with CBF with increases of 55.1\% and $149.5 \%$ for flexural strength and flexural modulus, respectively, when the filler content increased from 2 to $40 \mathrm{wt} \%$. This apparent increment could be attributed to the enhanced brittleness and stiffness of the composites.

The impact strength of a composite is influenced by many factors, including the toughness of the reinforcement, matrix fracture, the nature of the filler-matrix interfacial region, and frictional work involved in pulling out the filler from the matrix $[35,36]$. Among these, the nature of the interfacial region is significant and directly related to the toughness of the composite. For the CBF-filled composites, impact strength showed a small plateau followed by a significant deterioration. It increased from $65.3 \mathrm{~kJ} / \mathrm{m}^{2}$ for neat LDPE to $69.5 \mathrm{~kJ} / \mathrm{m}^{2}$ with a filler loading of $5 \mathrm{wt} \%$; however, further increasing the incorporation content to $40 \mathrm{wt} \%$ led to a decrement of impact strength to $15.8 \mathrm{~kJ} / \mathrm{m}^{2}$.

The evaluated mechanical properties showed that adding CBF could significantly increase the tensile strength, elastic modulus, flexural strength and flexural modulus of the LDPE composites. However, it
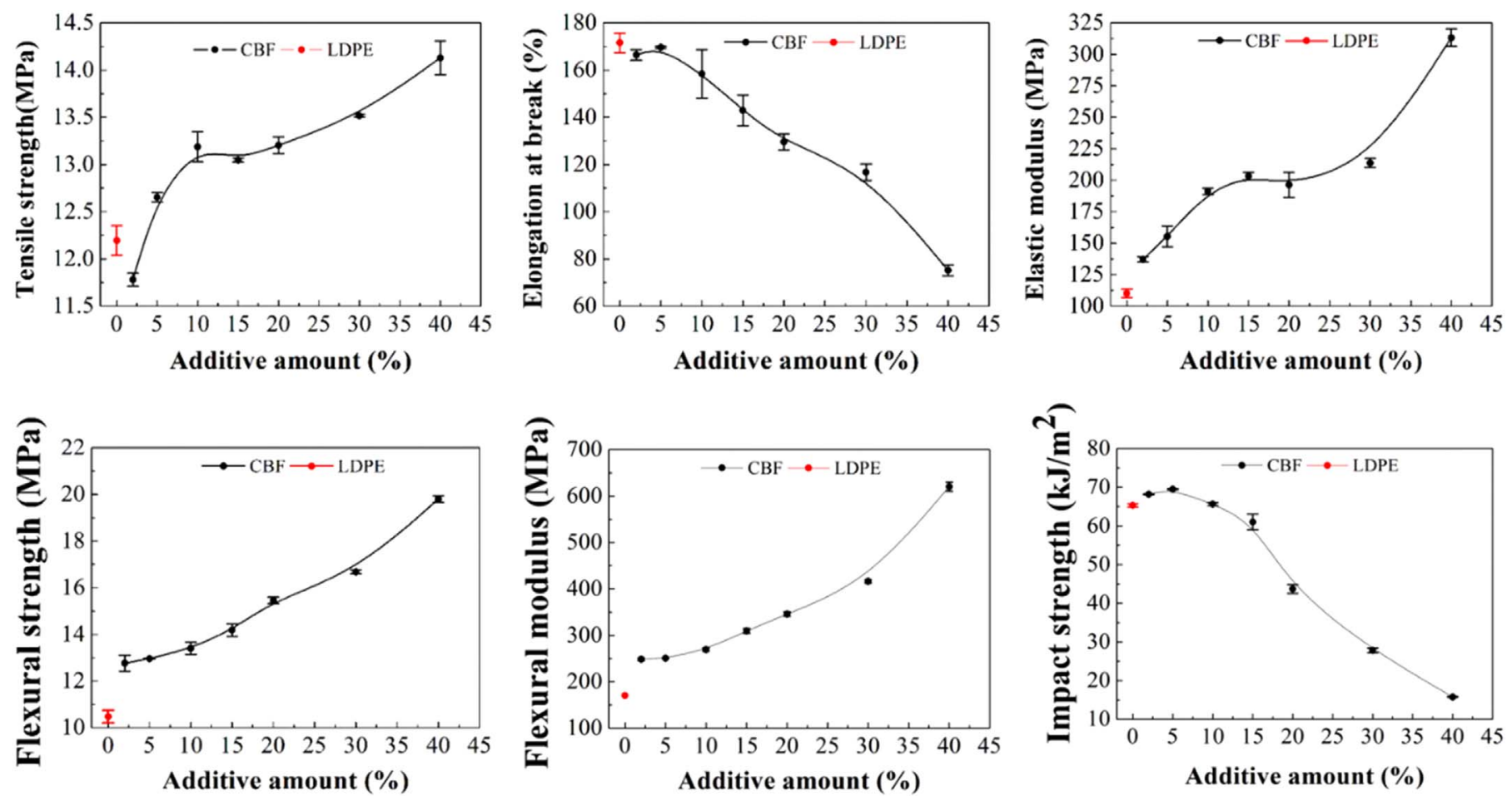

Fig. 6. Mechanical properties of neat LDPE and LDPE filled with CBF. 
resulted in a decrease in impact strength and elongation at break. Therefore, the inclusion of CBF mainly played a reinforcing role. The optimal amount of CBF was determined to be $5-15 \mathrm{wt} \%$ with a good balance between toughness and stiffness in the LDPE composites. It is worth noting that lubricants [37] and compatilizers [38] can also affect the mechanical performance of LDPE composites. These factors will be considered in future work.

\section{Conclusions}

The $\gamma_{S}^{D}$ profile for both CBF and POS showed that this component contributed the major part to the $\gamma_{S}^{T}$. The $\gamma_{S}^{D}$ changed as a function of surface coverage, indicating that they were energetically fairly heterogeneous. The $\mathrm{CBF}$ also showed lower $\mathrm{W}_{\mathrm{C}}$, which could reduce the filler particle-particle interactions, allowing its better dispersion in the LDPE matrix. Adding CBF could significantly improve the heat resistance of LDPE and the VST increased by $0.9-4.7^{\circ} \mathrm{C}$. In addition, it could significantly increase the tensile strength, elastic modulus, flexural strength and flexural modulus of the LDPE composites. The absence of toxic metal coupled with excellent mechanical performance makes CBF an ideal candidate as a biofiller for the masterbatch industry, potentially solving the significant problem of high levels of toxic metals in toys.

\section{Acknowledgements}

The authors gratefully acknowledge financial support from the National Natural Science Foundation of China (Grant nos. 51606055 and 41373121) and Zhejiang Provincial Natural Science Foundation of China (Grant no. LY14D010009).

\section{References}

[1] Noll W, Holm R, Born L. Painting of ancient ceramics. Angew Chem Int Ed Engl $1975 ; 14: 602-13$.

[2] Jansen M, Letschert HP. Inorganic yellow-red pigments without toxic metals. Nature 2000;404:980-2.

[3] Guney M, Zagury GJ. Heavy metals in toys and low-cost jewelry: critical review of U.S. and Canadian legislations and recommendations for testing. Environ Sci Technol 2012;46:4265-74.

[4] Guney M, Nguyen A, Zagury GJ. Estimating children's exposure to toxic elements in contaminated toys and children's jewelry via saliva mobilization. J Environ Sci Health Part A 2014;49:1218-27.

[5] Yao Z, Xia M, Ge L, Chen T, Li H, Ye Y, Zheng H. Mechanical and thermal properties of polypropylene (PP) composites filled with $\mathrm{CaCO}_{3}$ and shell waste derived biofillers. Fibers Polym 2014;15:1278-87.

[6] Fombuena V, Bernardi L, Fenollar O, Boronat T, Balart R. Characterization of green composites from biobased epoxy matrices and bio-fillers derived from seashell wastes. Mater Des 2014;57:168-74.

[7] Li H, Tan Y, Zhang L, Zhang Y, Song Y, Ye Y, Xia M. Bio-filler from waste shellfish shell: preparation, characterization, and its effect on the mechanical properties on polypropylene composites. J Hazard Mater 2012;217-218:256-62.

[8] Mustata F, Tudorachi N, Rosu D. Thermal behavior of some organic/inorganic composites based on epoxy resin and calcium carbonate obtained from conch shell of Rapana thomasiana. Compos Part B: Eng 2012;43:702-10.

[9] Voelkel A, Strzemiecka B, Adamska K, Milczewska K. Inverse gas chromatography as a source of physiochemical data. J Chromatogr A 2009;1216:1551-66.

[10] Voelkel A. Inverse gas chromatography in characterization of surface. Chemom Intell Lab 2004;72:205-7.

[11] Panzer U, Schreiber HP. On the evaluation of surface interactions by inverse gas chromatography. Macromolecules 1992;25:3633-7.
[12] Lavielle L, Schultz J. Surface properties of carbon fibers determined by inverse gas chromatography: role of pretreatment. Langmuir 1991;7:978-81.

[13] Smith RR, Williams DR, Burnett DJ, Heng JYY. A new method to determine dispersive surface energy site distributions by inverse gas chromatography. Langmuir 2014;30:8029-35.

[14] Ho R, Heng JYY. A review of inverse gas chromatography and its development as a tool to characterize anisotropic surface properties of pharmaceutical solids. KONA Powder Part J 2013;30:164-80.

[15] Jefferson AE, Williams DR, Heng JYY. Computing the surface energy distributions of heterogeneous crystalline powders. J Adhes Sci Technol 2011;25:339-55.

[16] Thielmann F, Burnett DJ, Heng JYY. Determination of the surface energy distributions of different processed lactose. Drug Dev Ind Pharm 2007;33:1240-53.

[17] Fowkes FM. Attractive forces at interfaces. Ind Eng Chem 1964;56:40-52.

[18] Dorris GM, Gray DG. Adsorption of n-alkanes at zero surface coverage on cellulose paper and wood fibers. J Colloid Interface Sci 1980;77:353-62.

[19] Swaminathan V, Cobb J, Saracovan I. Measurement of the surface energy of lubricated pharmaceutical powders by inverse gas chromatography. Int J Pharm 2006;312:158-65.

[20] van Oss CJ. Acid-base interfacial interactions in aqueous media. Colloids Surf A: Physicochem Eng Asp 1993;78:1-49.

[21] Van Oss CJ, Good RJ, Chaudhury MK. Additive and nonadditive surface tension components and the interpretation of contact angles. Langmuir 1988;4:884-91.

[22] de Kruif JK, Khoo J, Bravo R, Kuentz M. Novel quality by design tools for concentrated drug suspensions: surface energy profiling and the fractal concept of flocculation. J Pharm Sci 2013;102:994-1007.

[23] Legras A, Kondor A, Heitzmann MT, Truss RW. Inverse gas chromatography for natural fibre characterisation: identification of the critical parameters to determine the Brunauer-Emmett-Teller specific surface area. J Chromatogr A 2015;1425:273-9.

[24] Ahsan T, Taylor DA. The influence of surface energetics of calcium carbonate minerals on mineral-polymer interaction in polyolefin composites. J Adhes 1998;67:69-79.

[25] Rubio F, Rubio J, Oteo JL. Effect of the measurement temperature on the dispersive component of the surface free energy of a heat treated SiO2 xerogel. J Sol-Gel Sci Technol 2000;18:115-8.

[26] Purmalis O, Klavins M. Surface activity of humic substances within peat profile. In: Xu J, Wu J, He Y, editors. Functions of natural organic matter in changing environment. Netherlands: Springer; 2013. p. 341-6.

[27] Schmitt P, Koerper E, Schultz J, Papirer E. Characterization, by inverse gas chromatography, of the surface properties of calcium carbonate before and after treatment with stearic acid. Chromatographia 1988;25:786-90.

[28] Papirer E, Schultz J, Turchi C. Surface properties of a calcium carbonate filler treated with stearic acid. Eur Polym J 1984;20:1155-8.

[29] Jeong S, Yang Y, Chae Y, Kim B. Characteristics of the treated ground calcium carbonate powder with stearic acid using the dry process coating system. Mater Trans 2009;50:409-14.

[30] Fowkes FM. Calculation of work of adhesion by pair potential suummation. J Colloid Interface Sci 1968;28:493-505.

[31] Sun F, Littlejohn D, Gibson M David. Ultrasonication extraction and solid phase extraction clean-up for determination of US EPA 16 priority pollutant polycyclic aromatic hydrocarbons in soils by reversed-phase liquid chromatography with ultraviolet absorption detection1. Anal Chim Acta 1998;364:1-11.

[32] Oluseyi T, Olayinka K, Alo B, Smith RM. Improved analytical extraction and clean up techniques for the determination of PAHs in contaminated soil samples. Int $\mathrm{J}$ Environ Res 2011;5:681-90.

[33] Zhang S, Cao XY, Ma YM, Ke YC, Zhang JK, Wang FS. The effects of particle size and content on the thermal conductivity and mechanical properties of Al2O3/high density polyethylene (HDPE) composites. Express Polym Lett 2011;5:581-90.

[34] Ayrilmis N, Kaymakci A, Ozdemir F. Physical, mechanical, and thermal properties of polypropylene composites filled with walnut shell flour. J Ind Eng Chem 2013;19:908-14.

[35] Arsalan N, Buiting JJ, Nguyen QP. Surface energy and wetting behavior of reservoir rocks. Colloids Surf A: Physicochem Eng Asp 2015;467:107-12.

[36] Zhong JB, Lv J, Wei C. Mechanical properties of sisal fibre reinforced urea formaldehyde resin composites. Express Polym Lett 2007;1:681-7.

[37] Huda MS, Drzal LT, Mohanty AK, Misra M. Chopped glass and recycled newspaper as reinforcement fibers in injection molded poly(lactic acid) (PLA) composites: a comparative study. Compos Sci Technol 2006;66:1813-24.

[38] Yang J, Li Z, Liu J. Effects of compatilizers on the cellular structures, interfacial morphologies and mechanical properties of PP foam composites. E-Polymers 2011;11:822-31. 